\title{
CUATRO DIBUJOS DE SEBASTIÁN MUÑOZ PARA LA MANTERÍA
}

\author{
Juan Carlos Gómez Aragüete ${ }^{1}$ \\ Licenciado en Bellas Artes, Universidad Complutense de Madrid \\ Teresa Zapata Fernández de la HoZ ${ }^{2}$ \\ Doctora en Historia del Arte, Universidad Autónoma de Madrid
}

\begin{abstract}
Los frescos de la Iglesia de Santo Tomás de Villanueva de Zaragoza, conocida como La Mantería, constituyen el mayor conjunto decorativo conservado de Claudio Coello. Según Antonio Palomino, el pintor trabajó en ellos más de un año, si bien cuando su discípulo Sebastián Muñoz regresó de su estancia en Italia se fue a Zaragoza a ayudarle. En este artículo se estudia una serie de dibujos preparatorios para dichos frescos, que confirman las palabras de Palomino y obligan a reconsiderar el papel jugado por Muñoz en la elaboración de la obra.
\end{abstract}

Palabras clave: La Mantería; dibujos; Claudio Coello; Sebastián Muñoz.

\section{FOUR DRAWINGS BY SEBASTIÁN MUÑOZ FOR LA MANTERÍA}

The frescoes held at Santo Tomás de Villanueva Church in Zaragoza, known as La Mantería, make up the largest preserved decorative collection of Claudio Coello. According to Antonio Palomino, the painter worked on this collection for more than a year, although his disciple Sebastián Muñoz assisted him in Zaragoza upon his return from Italy. This article examines a series of preparatory drawings for these frescoes, which confirm Palomino's words and call for a reconsideration of the role played by Muñoz in the creation of this work of art.

Key words: La Mantería; drawings; Claudio Coello; Sebastián Muñoz.

Cómo citar este artículo / Citation: Gómez Aragüete, Juan Carlos / Zapata Fernández de la Hoz, Teresa (2020) "Cuatro dibujos de Sebastián Muñoz para La Mantería”. En: Archivo Español de Arte, vol. 93, núm. 372, Madrid, pp. 335-346. https://doi.org/10.3989/aearte.2020.22

La fundación en Zaragoza del Colegio de Santo Tomás de Villanueva de la orden agustina, llamado de la Mantería ${ }^{3}$, tuvo su origen a la muerte de don Martín de Funes y Copones, noble caballero de la ciudad, devoto de la orden, que murió con voto de ingresar en la misma, quien había nombrado al agustino fray Pedro Alcomeche, entre otros, ejecutor de una parte de sus bienes para distribuirlos en obras pías, que la comunidad decidió emplear en la fundación de un colegio bajo la advocación de santo Tomás de Villanueva, lo que tuvo lugar el 19 de abril de 1629, en unas casas del Coso propiedad del racionero de la Seo, Doctor la Huerta ${ }^{4}$.

1 jcgomezaraguete@gmail.com / ORCID iD: https://orcid.org/0000-0001-6789-5564

2 teresa.zfh@gmail.com / ORCID iD: https://orcid.org/0000-0001-9926-5903

3 En la actualidad, Colegio Calasanz de Zaragoza.

${ }^{4}$ Claver Ferrer, 2000: 222-223. Sobre el origen y la fundación del colegio, véase también: Paniagua Miguel, 2009 : 103 y ss. 


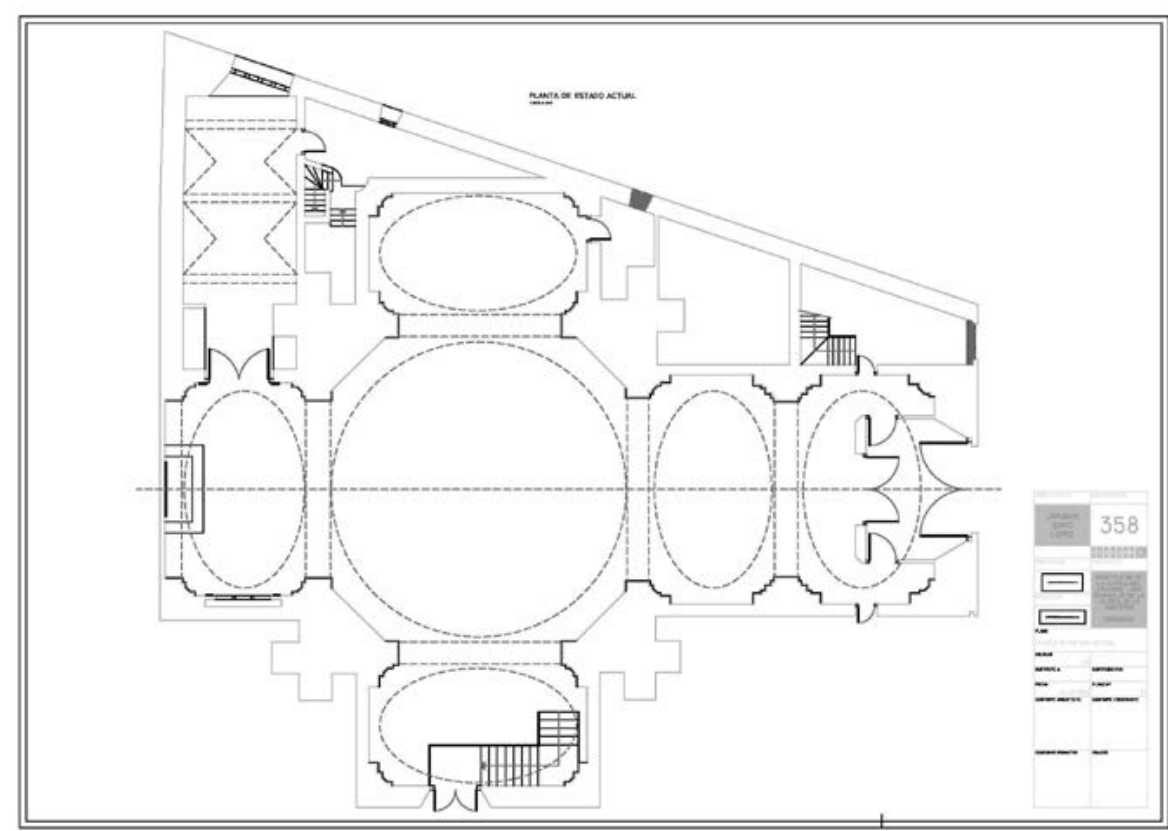

Fig. 1. Plano de La Mantería. Cortesía de Joaquín Soro López.

Solo ocho días permanecieron en las casas del Coso, de donde les desalojaron por no haber solicitado la licencia de fundación al ayuntamiento, sin que pudieran regresar por haberlas comprado sobre palabra, sin mediar escritura. Se trasladaron entonces a unas casas de la calle Juan Garro, cerca del puente de tablas sobre el río Ebro. Años después, muertos el fundador y primer rector del colegio, fray Pedro Alcomeche, y su sucesor, su hermano, fray Jerónimo Alcomeche, su sustituto, fray Francisco Llosas, compró unas casas en la Mantería ${ }^{5}$ por 6.000 escudos, que por falta de la licencia arzobispal tuvieron que abandonar y regresar a las casas del puente. Allí permanecieron hasta el año 1663, en que, fallecido el arzobispo de Zaragoza, fray Juan Cebrián, de la Orden de la Merced, su sucesor, fray Francisco de Gamboa, del convento de los agustinos de Salamanca, favoreció su regreso a la Mantería en el mes de marzo y la ayuda necesaria para la construcción definitiva en el mismo lugar de un colegio y un templo ${ }^{6}$. Las obras se prolongaron hasta $1685^{7}$, siendo consagrada la iglesia en el mes de junio de $1686^{8}$, una vez finalizada la decoración pictórica de su interior, en la que se centra el contenido de esta investigación.

La planta del templo dibuja una cruz latina articulada en seis tramos cubiertos por cúpulas, la del crucero de mayor tamaño, semiesférica apoyada sobre un tambor o cimborrio octogonal elevado sobre cuatro arcos torales, y las otras cinco, ovoides sobre pechinas. Todas disponen de una linterna por la que penetra la luz natural [fig. 1].

La austeridad de su interior, en cuyas paredes se apoyan pilastras de orden toscano con su entablamento adornado con modillones y cornisas corridas, ha hecho suponer que desde un prin-

5 En la antigua morería, sede del gremio de los artesanos manteros, de donde tomaría su denominación popular (Monedero Granados, 1999: 18).

${ }^{6}$ Otra ayuda importante fue la del obispo de Huesca, fray Bartolomé de Foncalda, agustino también, lo que unido a otras limosnas obtenidas por fray Lorenzo de Segovia, del Convento de San Agustín, permitió la construcción de la iglesia y del claustro. Véanse: Claver Ferrer, 2000: 225. Paniagua Miguel, 2009: 108-109.

7 En noviembre de ese año se vendió un "treudo" con el fin de conseguir dinero para trasladar el Santísimo, pues el colegio se hallaba "con algunos empeños", "procedidos de los grandes gastos que ha tenido el concluir la fábrica y ornato de la iglesia" (Rojas Serrano, 2000: 45).

8 El día 26, miércoles, el arcediano mayor de Santa María en la Iglesia Metropolitana de Zaragoza, don Antonio de Segovia, bendijo la iglesia, y el 29 por la tarde se trasladó el Santísimo Sacramento y se cantaron las vísperas de la dedicación. El 30 se hizo la fiesta (Claver Ferrer, 2000: 225-226). 
cipio se pensó en decorarlo con pinturas murales, con las que se cubrieron la totalidad de las seis cúpulas y las paredes hasta el suelo9.

Antonio Palomino, en su indispensable obra El Parnaso español pintoresco laureado, al referirse a La Mantería escribe que la decoración, al fresco, se contrató con Claudio Coello en $1683^{10}$, en la que se ocupó más de un año, "y la executó muy á la satisfaccion de todos los interesados, é inteligentes en el Arte" 11 , sin que hasta el momento se haya localizado el contrato, ni en su expediente personal se mencione su estancia en Zaragoza ${ }^{12}$.

La ambiciosa decoración se ajusta a un programa iconográfico de exaltación de santo Tomás de Villanueva y de la orden agustina, elaborado sin duda por algún miembro de la orden, quien se lo proporcionaría al pintor ${ }^{13}$.

En esas fechas, Coello había demostrado su habilidad como pintor decorativo, tanto en pinturas murales como de carácter efímero para fiestas públicas, al fresco y al temple, solo o en colaboración con su compañero José Donoso. Juntos habían decorado varias iglesias de Madrid ${ }^{14}$, la Casa de la Panadería en la Plaza Mayor ${ }^{15}$, el techo del vestuario de la Catedral de Toledo ${ }^{16}$, la sala de capítulo de la Cartuja del Paular ${ }^{17}$ y la torre del cuarto de la reina del Palacio Real, con motivo de la llegada a la corte de la primera mujer de Carlos II, María Luisa de Orleáns, además de una destacada participación en las arquitecturas efímeras levantadas para recibirla ${ }^{18}$.

Prosiguiendo el relato de Palomino, cuando Coello llevaba algún tiempo trabajando en la Iglesia de Santo Tomás, su discípulo Sebastián Muñoz (h. 1654-1690) le avisó de su regreso de Roma, a lo que el maestro le respondió que se trasladara a Zaragoza para ayudarle en las pinturas de la iglesia, como así hizo ${ }^{19}$. Según el autor del Parnaso español, Muñoz colaboró con su maestro en los cuadros de historias que decoraban los arcos de triunfo y demás adornos con los que la villa de Madrid recibió a María Luisa de Orleáns, en enero de $1680^{20}$, trabajo que le permitió realizar con veintiséis años el soñado viaje a Roma, sin duda, el acontecimiento más importante en la vida artística del pintor, donde permaneció hasta 1684 completando su formación en el taller de Carlo Maratta ${ }^{21}$.

La correcta catalogación y estudio de una serie de dibujos para las pinturas que debían decorar la iglesia de la Mantería, conservados en la Biblioteca Nacional de España, objeto de esta publicación, evidencian que la participación de Muñoz fue más allá de una simple colaboración, como hasta ahora se había supuesto, tal y como correspondía a un pintor formado en Italia.

\footnotetext{
9 Véase: Chamoso Lamas, 1953: 11-12.

${ }^{10}$ Según Antonio Claver, fue el padre fray Juan del Cerro, rector del colegio, quien concluyó la iglesia y la hizo pintar al fresco (Claver Ferrer, 2000: 225).

11 Palomino de Castro y Velasco, 1796: 654.

12 Sullivan (1989: 83 y 308) cree que un pago de 3.750 maravedís de vellón en concepto del impuesto de la media anata, realizado por Coello el 2 de marzo de 1684, podría estar relacionado con la decoración de La Mantería.

${ }_{13}$ Para el programa iconográfico, véase: Latre González, 1984.

14 Palomino cita la Iglesia de Santa Cruz, donde decoraron el presbiterio; la sacristía y la capilla de san Ignacio, llamada de los Borjas, en el Colegio Imperial de los jesuitas; las pechinas de la iglesia del convento de los Basilios y las de la Iglesia de la Santísima Trinidad (Palomino de Castro y Velasco, 1796: 628 y 652-653).

15 Terminada la reconstrucción de la Casa de la Panadería en la Plaza Mayor de Madrid, casi destruida por un incendio en 1672, el ayuntamiento contrató a Donoso y Coello para decorar al temple los techos del Salón Real, su antecámara y la escalera de acceso, con arquitecturas fingidas y figuras alegóricas, que se comprometieron a dar acabadas en marzo de 1674. Véase: Guerra Sánchez-Moreno, 1931: 373-374 y 386-388, doc. 7.

16 Durante los meses de junio y julio de 1674 (Revenga Domínguez, 2002: 274).

17 Según Palomino, Coello y Donoso pintaron dos historias en el techo de la sala, "hacia los escaños". La de Donoso representaba a san Benito y san Antonio Abad ofreciendo sus hijos a san Bruno (Palomino de Castro y Velasco, 1796: 628 y 652).

18 Palomino de Castro y Velasco, 1796: 653-654. Para su participación en estas decoraciones, véase: Zapata Fernández de la Hoz, 2000: 54 y ss.

19 Palomino de Castro y Velasco, 1796: 640.

${ }^{20}$ Aunque su nombre no figura entre los pintores que trabajaron en los arcos, sí aparece un Sebastián Muñoz como testigo en el contrato que firmaron José Donoso, Claudio Coello y Matías de Torres y los pintores a los que dieron participación, que podría tratarse del pintor (Zapata Fernández de la Hoz, 2000: 55).

${ }_{21}$ Sobre Sebastián Muñoz, véanse: Palomino de Castro y Velasco, 1796: 640-644. Cean Bermúdez, 1800: 216-219. Martínez Ripoll, 1985; 2008. Pérez Sánchez, 1986: 271-274; 2003: 352 y 355-358. Aterido, 2002; 2016.
} 

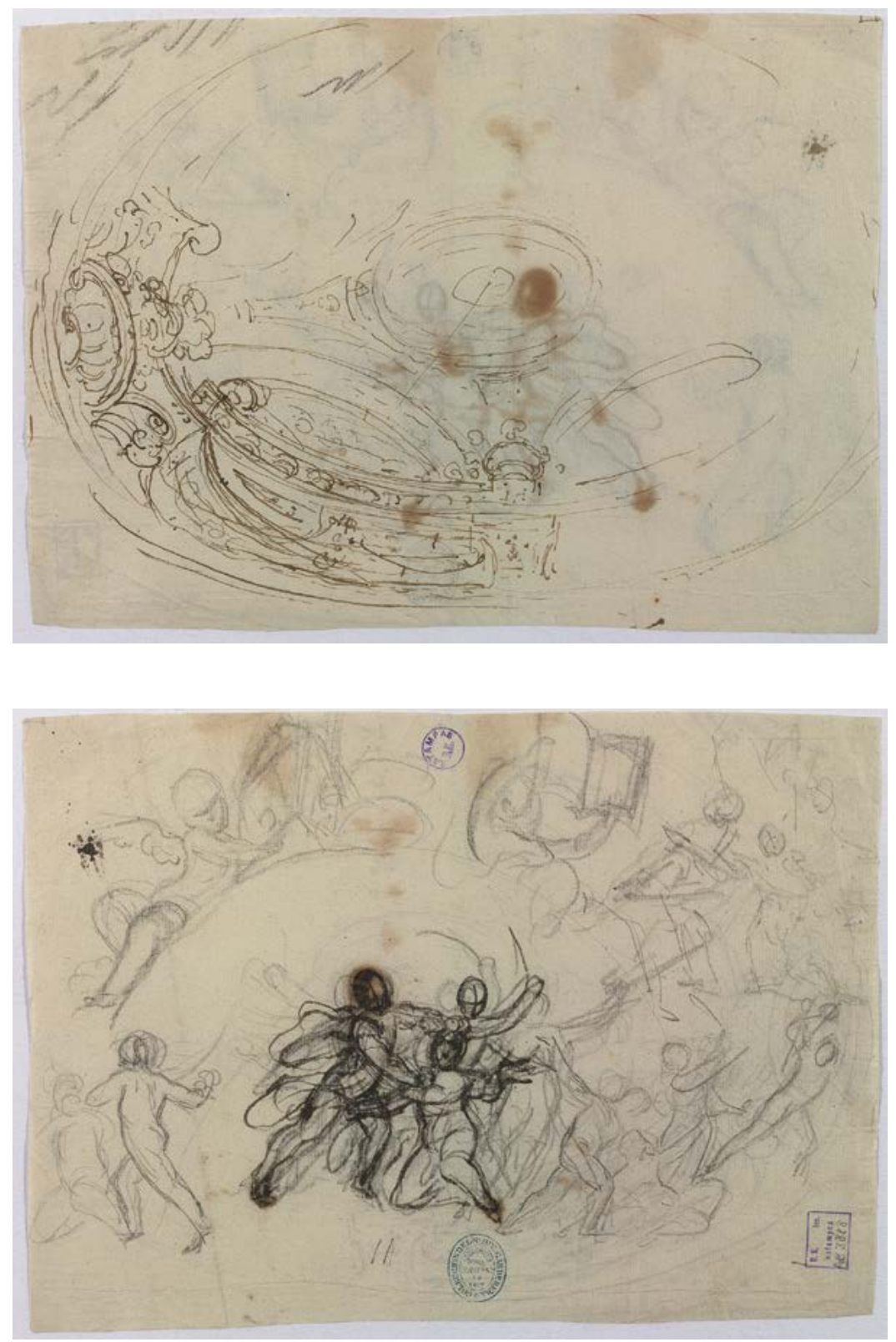

Fig. 2. Sebastián Muñoz, Proyecto para la decoración de la cúpula del coro de La Mantería. Biblioteca Nacional de España, Madrid.
Fig. 3. Sebastián Muñoz, Proyecto para la decoración de la cúpula del coro de La Mantería (reverso). Biblioteca Nacional de España, Madrid.

El primero [figs. 2 y 3] fue publicado como anónimo romano del siglo XVII, con el título de Proyecto de decoración de una cúpula ${ }^{22}$. Hace unos años, formó parte de la exposición Góngora. La estrella inextinguible, como Dibujo preparatorio de una cúpula (Angélica y Medoro), de Sebastián Muñoz $^{23}$, sin duda porque en el reverso figuran unos apuntes identificados como una escena del episodio amoroso entre los dos amantes incluido en el célebre poema épico-caballeresco de Ludovico Ariosto, Orlando furioso $(1532)^{24}$, asunto representado por Muñoz, según

22 VV. AA., 1991: 197, núm. 272. Signatura: DIB/18/1/3888. Lápiz negro y tinta marrón sobre papel verjurado ahuesado. $188 \times 216 \mathrm{~mm}$.

${ }^{23}$ Roses Lozano, 2012: 402.

${ }^{24}$ Canto 19,9 y ss. 


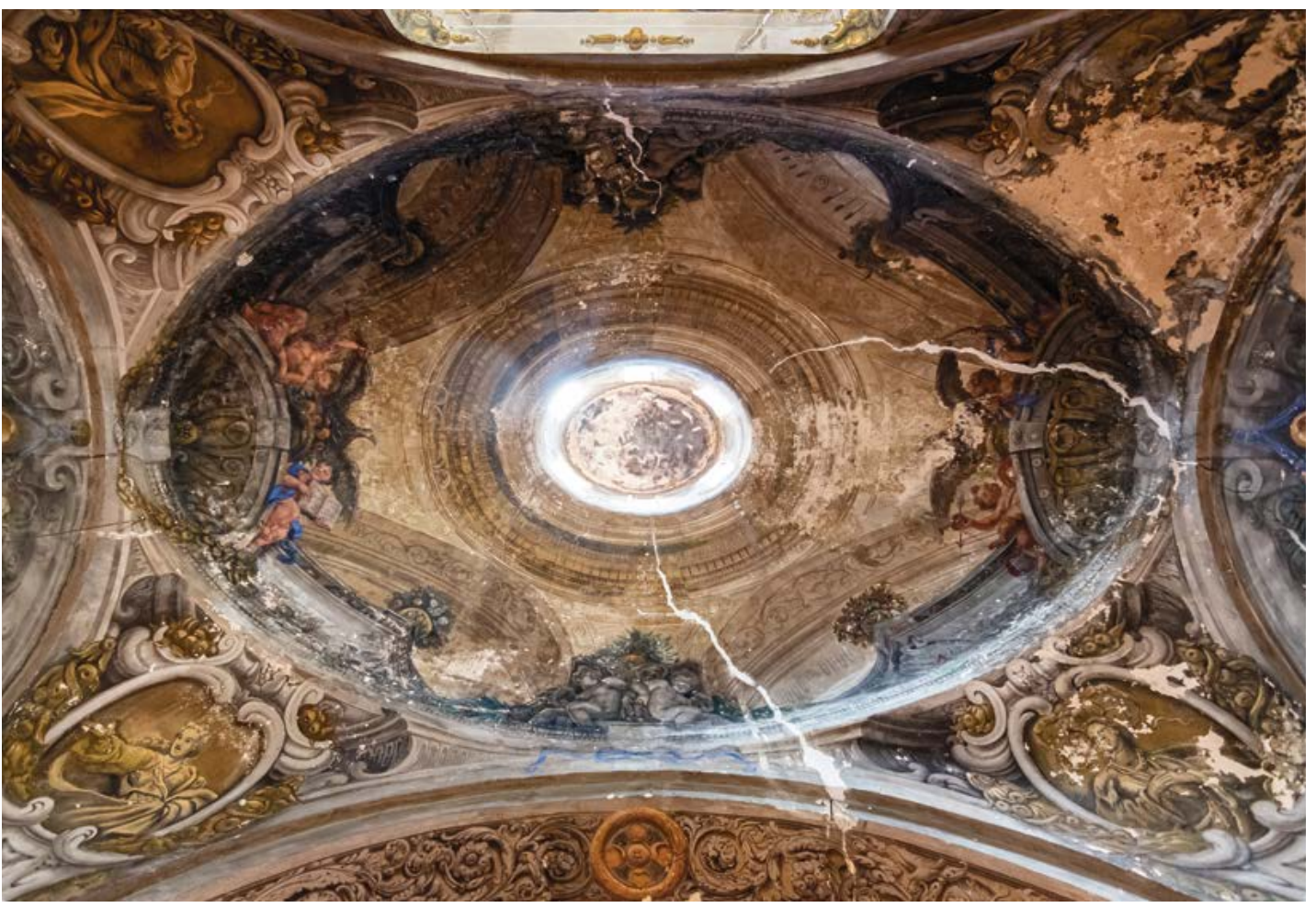

Fig. 4. Vista general de la cúpula del coro de La Mantería. Foto cortesía de Javier Domingo.

Palomino, en un techo del Palacio Real de Madrid ${ }^{25}$, sin reparar en que el espacio a decorar era rectangular, como se aprecia en el dibujo que se conserva en la Biblioteca Nacional de España ${ }^{26}$.

La cara principal del dibujo es un apunte para la decoración de una cúpula ovalada, en cuyo centro se esboza la apertura de un óculo o una linterna. En el cuarto inferior izquierdo, en el que se centra el autor, se distinguen diferentes elementos decorativos, como jarrones, veneras y roleos. Apoyada en el tambor, una barandilla de balaustres, antepecho de los arcos de medio punto abiertos en la cúpula [fig. 2].

En el reverso [fig. 3], obviando de momento el grupo de figuras centrales, en su mitad superior se aprecia una forma circular sobre la que, a uno y otro lado de un jarrón, se sientan dos niños que sostienen, el de la derecha, un libro, y el de la izquierda, un libro y un tintero, elementos que lo identifican como un boceto para la decoración de una de las cúpulas ovoides de la iglesia de la Mantería, en concreto, la del coro, la primera según se entra en la iglesia [fig. 4].

La cúpula se dedicó al santo titular, santo Tomás de Villanueva, a quien aluden los símbolos que la decoran: un corazón flamígero atravesado por una flecha y un arco y una flecha, en un extremo del eje mayor, y una pluma y un libro abierto, en el extremo opuesto, todos bajo las alas protectoras de un águila ${ }^{27}$. El principal es el corazón atravesado por una flecha, emblema de la orden agustina, adoptado por Tomás para manifestar su adhesión a la orden, en cuyo escudo figuraba atravesado por una o tres flechas ${ }^{28}$.

25 Palomino de Castro y Velasco, 1796: 640.

26 Signatura: DIB/15/2/27. Lápiz negro y tinta marrón sobre papel verjurado ahuesado. 178 x $258 \mathrm{~mm}$. Reproducido en: Roses Lozano, 2012: 402.

27 El libro y la pluma aluden a los escritos de santo Tomás. El arco y la flecha quizás aludan a la elocuencia del santo, cuyas palabras serían como flechas lanzadas por un arco.

${ }^{28}$ Cuando aparece con una sola, como aquí, alude a estas palabras de san Agustín (Confesiones, libro IX, 2, 3): Sagittaveras tu cor meum charitate tua (Habías herido mi corazón con las flechas de tu amor) (Réau, 1996-1997, tomo 2, vol. 3: 38). 
Estos símbolos se completan con las cuatro alegorías representadas en las pechinas: la Vigilancia y la Elocuencia, en las del lado del Evangelio; la Oración y la Firmeza, en las de la Epístola, acompañadas de las inscripciones: VIGILANTIA PASTOR. ELOQUENTIA INFORMANS. (La Vigilancia [es] pastor. Elocuencia que informa), y: ORATIO SALUTIS ANCLA. THUS ARDENS IN IGNE. (La Oración [es] áncora de salvación. Incienso que arde en el Fuego), ambas escritas sobre los arcos de los muros laterales. De ellas, la iconografía de la Firmeza está inspirada en la difundida obra de Cesare Ripa, Iconología ${ }^{29}$, donde escribe que la Firmeza del Amor debe representarse como una mujer tocada con dos anclas, entre las que se pintará un corazón unido a ellas mediante una bella ligadura, rodeado del lema: "Mens est firmissima". Es bastante probable que la iconografía de las otras tres, de las que no se distinguen bien los símbolos, a causa de los repintes, se hubiera inspirado igualmente en Ripa.

Para esta cúpula existe un dibujo de Claudio Coello en el Musée du Louvre ${ }^{30}$, que incluye una pechina, un balcón con balaustres pintado en el muro y una sección de la cúpula, en la que, a la derecha, se distinguen el angelito con el corazón atravesado por una flecha y parte del águila sobre un jarrón. El acabado del dibujo, su tamaño (391 x $263 \mathrm{~mm}$ ), el punto de vista, la sección de circunferencia que lo delimita por la parte superior derecha —el espacio vacío coincidiría con el intradós del arco que separa las cúpulas - , nos hace pensar que no se trata de otro dibujo preparatorio, sino de un dibujo realizado a posteriori por Coello como modelo para pintar las siguientes cúpulas, teniendo en cuenta que en los otros cuartos se repiten los elementos decorativos. Otra hipótesis es que Coello lo dibujara como recuerdo para utilizarlo en trabajos posteriores.

Al tratarse de un dibujo seguro del artista, cabría la posibilidad de que el anterior también fuera suyo. Sin embargo, la diferencia de técnica y modelos, relacionados con el estilo de Bernini y sus discípulos romanos cuando se catalogó como un dibujo italiano ${ }^{31}$, unido al hecho de que los estudios del reverso se hayan relacionado con la historia de Angélica y Medoro para el techo del Palacio Real, apuntan a Muñoz, formado en Roma con Carlo Maratta, como se ha indicado, como su autor.

En cuanto al grupo central del reverso del primer dibujo [fig. 3], parece evidente que representa una escena de martirio, con un personaje que sujeta a la víctima mientras se ejecuta el castigo. Alrededor, el autor ha esbozado los mismos personajes en diferentes posturas. Sin duda, Muñoz reutilizó la hoja de papel para lo que pensamos que sería una escena religiosa, como evidencia el grupo del ángulo superior derecho.

Un esbozo más acabado de este grupo lo encontramos en otro dibujo de la Biblioteca Nacional [fig. 5], identificado también erróneamente como apuntes para la misma escena de Angélica y Medoro ${ }^{32}$. En el grupo de la parte derecha, un verdugo o sayón se dispone a apuñalar a la figura arrodillada, claramente un religioso, como indica el hábito que le cubre, el mismo apenas esbozado en el dibujo anterior.

La otra cara de este dibujo [fig. 6] es una primera idea para una de las cartelas que decoran las dos cúpulas de los brazos del crucero, para las que se conserva otro dibujo del que trataremos a continuación.

Como se puede observar, la arquitectura está más cercana a la cúpula del coro, y la parte figurativa nos permite apreciar los cambios respecto al otro dibujo. La bicha la representó el pintor como una figura femenina sentada y apoyada sobre una parte de una arquitectura esquinada, con las piernas transformadas después en una cola de sirena. En segundo lugar, dibujó dos modelos de alas, de las que al final optó por el de la derecha. Por último, el jarrón que corona la arquitectura, ausente en el dibujo definitivo, sí es el mismo modelo pintado en las dos primeras cúpulas - las cúpulas de la nave-, mientras que la cartela se ha sustituido por una guirnalda.

Las dos cúpulas de los brazos del crucero son idénticas entre sí, al igual que las de los tramos de la nave. En ambas se repiten los mismos elementos decorativos, excepto los símbolos que las iden-

29 Ripa, 1987, vol. 1: 436.

30 Núm. de inv.: RF 43409. Lápiz negro, tinta marrón y aguadas marrón y parda sobre papel verjurado agarbanzado. Véanse: Sullivan, 1989: 260, D26. Boubli, 2002: 85-86, núm. 70.

31 Véase nota 22.

32 Roses Lozano, 2012: 402. Signatura: DIB/18/1/3887. Lápiz negro sobre papel verjurado ahuesado. 193 x 175 mm. 
Fig. 5. Sebastián Muñoz, Proyecto para la decoración de las cúpulas de los brazos del crucero de La Mantería (reverso). Biblioteca Nacional de España, Madrid.

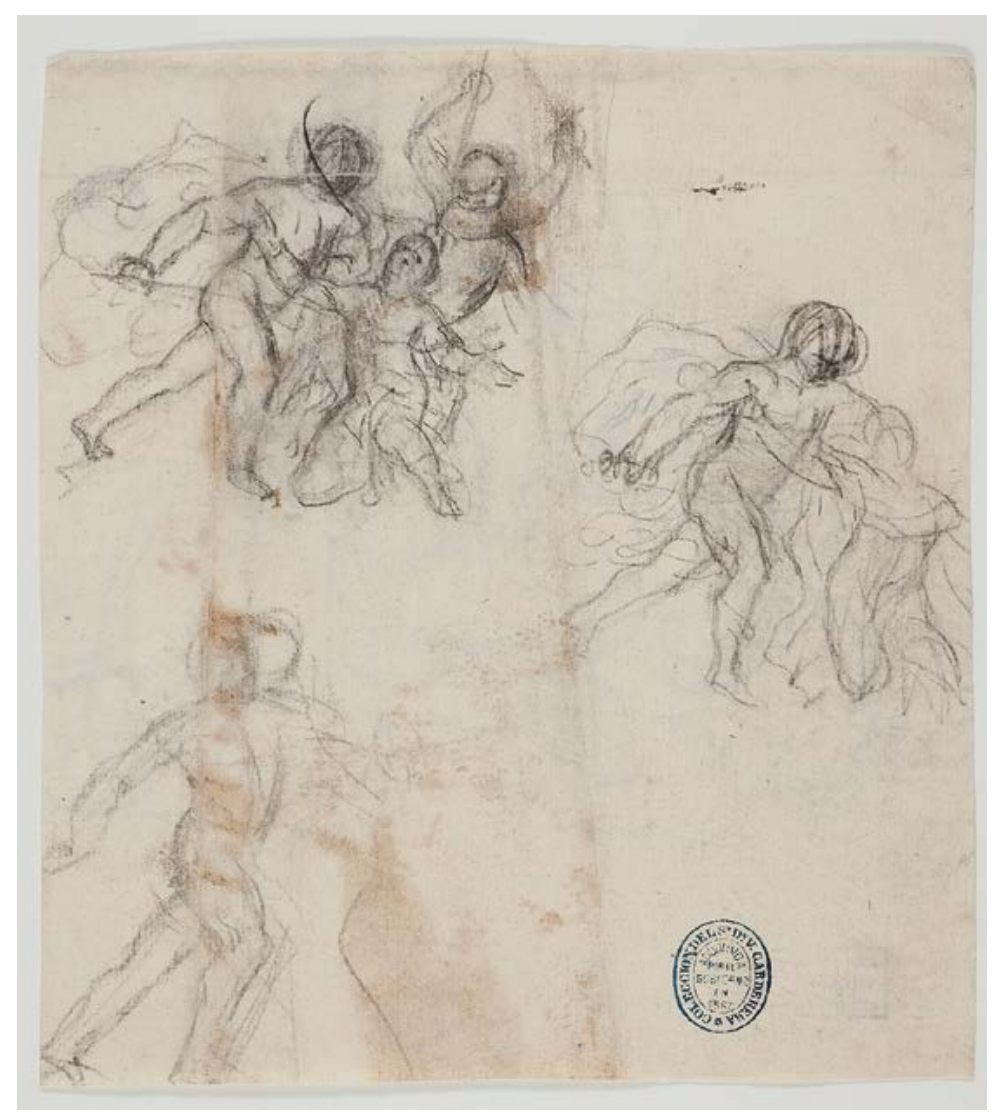

Fig. 6. Sebastián Muñoz, Proyecto para la decoración de las cúpulas de los brazos del crucero de La Mantería. Biblioteca Nacional de España,

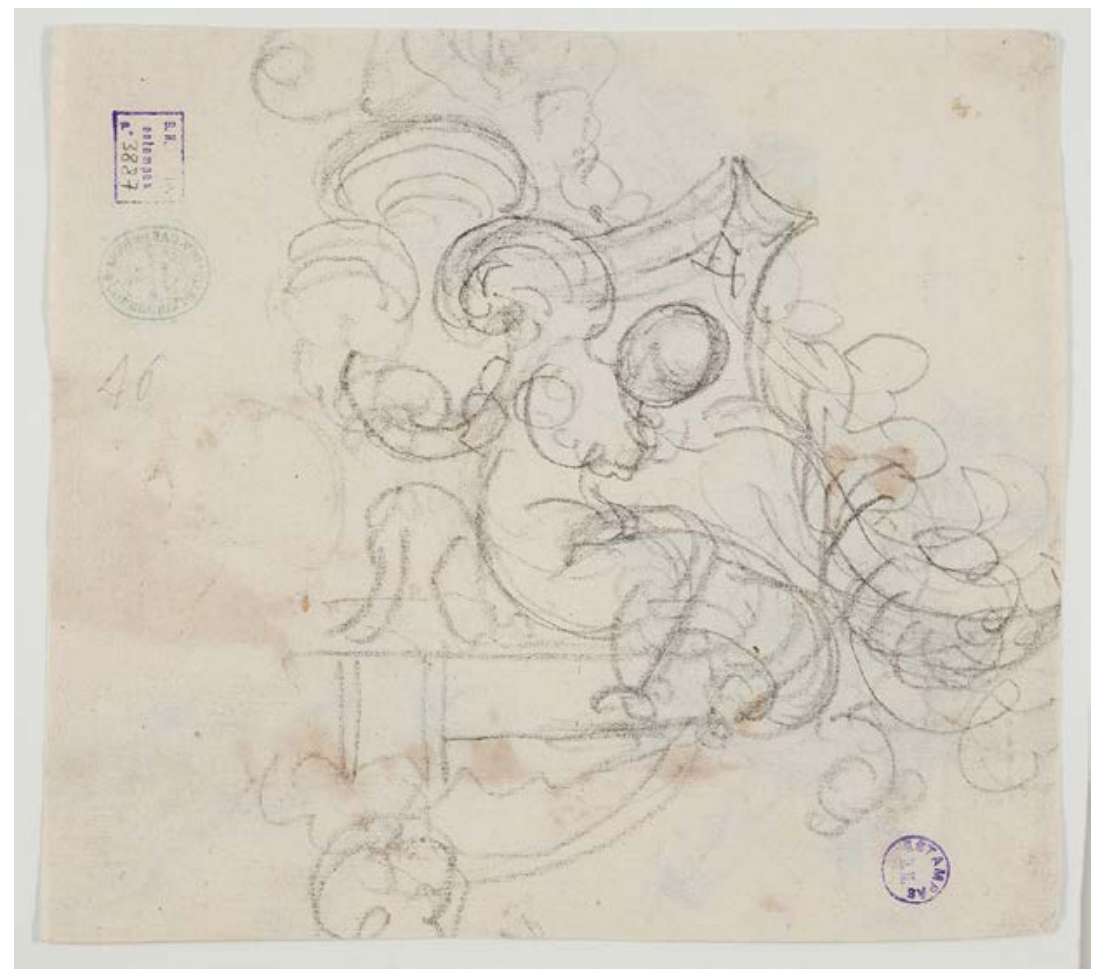

Archivo Español de Arte, vol. XCIII, n. ${ }^{\circ}$ 372, pp. 335-346, octubre-diciembre 2020 ISSN: 0004-0428, eISSN: 1988-8511, https://doi.org/10.3989/aearte.2020.22 
tifican, representados en cartelas en los extremos de los ejes, así como en las pechinas y en los arcos $\mathrm{y}$ - probablemente - en las linternas, prácticamente perdidas. Estos símbolos, fáciles de identificar, como comprobaremos a continuación, se refieren a la Pasión de Cristo, en la cúpula de la Epístola, y a la Virgen María, en la del Evangelio, siguiendo sin duda lo indicado en el programa iconográfico.

$\mathrm{Su}$ decoración sorprende por la riqueza y la originalidad de los elementos que la conforman, que imitan el bronce dorado y el mármol blanco, alternativamente. En los extremos del eje mayor de cada cúpula, sobresalen dos piezas trapezoidales de mármol fingido que ascienden, abriéndose en forma de horquilla, hasta la base de la linterna. Estas piezas sirven de soporte y marco a dos cartelas doradas que contienen símbolos alusivos, cada una flanqueada por una pareja de angelitos sentados sobre roleos. En los extremos del eje menor, dos parejas de bichas con las alas extendidas sirven de marco a otras tantas cartelas ricamente decoradas con roleos, flores y frutos. Robustos angelotes decoran las pechinas y los arcos [fig. 7].

Los símbolos representados en las cartelas de la cúpula de la Epístola son: en las del eje mayor, un farol, en una, y una oreja y una espada, en la otra, símbolos que se refieren al prendimiento de Cristo ${ }^{33}$; en las del eje menor, el lienzo con la impresión de la Santa Faz, recompensa de Cristo a Verónica por haberle secado con su velo el sudor de su rostro ${ }^{34}$, en un lado, y la corona de espinas, la caña con la esponja y la lanza, en el otro ${ }^{35}$.

Otros símbolos de la Pasión de Cristo, que portan angelitos, como las tenazas, el martillo, la caña y la cartela del INRI, decoran las pechinas sobre las que se sustenta la cúpula.

Por último, en los arcos, difíciles de distinguir por su mal estado de conservación, la columna de los azotes y la lanza con la que un soldado atravesó el costado de Cristo ${ }^{36}$. Las inscripciones que los acompañan son las siguientes: DISCIPLINA PACIS NOSTRAE SUPER EUM (El castigo de nuestra paz sobre Él) ${ }^{37}$ y ANGELI PACIS AMARE FLEBUNT (Los ángeles de paz llorarán amargamente) ${ }^{38}$.

Las correspondientes cartelas de la cúpula del Evangelio, que se derrumbó durante la última restauración ${ }^{39}$, se decoraban, la de un lado, con una imagen de la Virgen, aunque su aspecto actual era el resultado de los sucesivos repintes; la del otro, con una Puerta, símbolo que alude a una de las letanías del rosario, en la que se la invoca como Ianua Coeli, "puerta del cielo", en referencia a la función de mediadora que se le atribuye en la salvación. En las cartelas del eje mayor se distinguían con dificultad ramos de flores. Finalmente, en las pechinas, otros símbolos marianos, como lirios y azucenas, símbolos de pureza, y en los arcos, jarrones con más flores, acompañados de otras dos letanías: ROSA MISTICA (Rosa mística) y SPECULUM IUSTITIE (Espejo de justicia).

El siguiente dibujo [fig. 8], catalogado como anónimo genovés del siglo XVII ${ }^{40}$, es otro proyecto para las cartelas que decoran las cúpulas de los brazos del crucero.

El dibujo representa la parte derecha de una exuberante cartela de decoración barroca a base de volutas o roleos vegetales, sostenida por un águila con las alas extendidas. La parte central se enmarca por una corona de hojas de laurel rematada por la cabeza de un angelito. A la derecha, sentada sobre la arquitectura, una bicha con las alas desplegadas.

${ }^{33}$ La oreja y la espada aluden a un episodio del prendimiento, cuando Pedro, para defender a su maestro, se abalanzó sobre Malco, siervo del sumo sacerdote, y le cortó la oreja derecha (Juan, 18, 10).

34 Réau, 1996-1997, t. 1, vol. 2: 483.

${ }^{35}$ Los símbolos de estas dos cartelas fueron eliminados durante la última restauración por considerarse añadidos posteriores. Véase: López Gómez/Senserrich Espuñes, 2001: 52-53.

36 "Pero al llegar a Jesús, como lo vieron ya muerto, no le quebraron las piernas, sino que uno de los soldados le atravesó el costado con una lanza y al instante salió sangre y agua.” (Juan, 19, 33-34).

37 "Siendo así que por causa de nuestras iniquidades fue Él llagado, y despedazado por nuestras maldades; el castigo de que debía nacer nuestra paz con Dios descargó sobre Él, y con sus cardenales fuimos nosotros curados." (Isaías, 53, 5).

38 "Pero he aquí que desde afuera gritarán los que vean venir a los enemigos: llorarán amargamente los ángeles o embajadores encargados de la paz." (Isaías, 33, 7).

39 Véase: Lorenzo Lizalde/Soro, 2008: 187 y ss.

${ }^{40}$ VV. AA., 1991: 186, núm. 250. Signatura: DIB/18/1/3906. Lápiz negro y tinta marrón sobre papel verjurado ahuesado. $200 \times 154 \mathrm{~mm}$. 


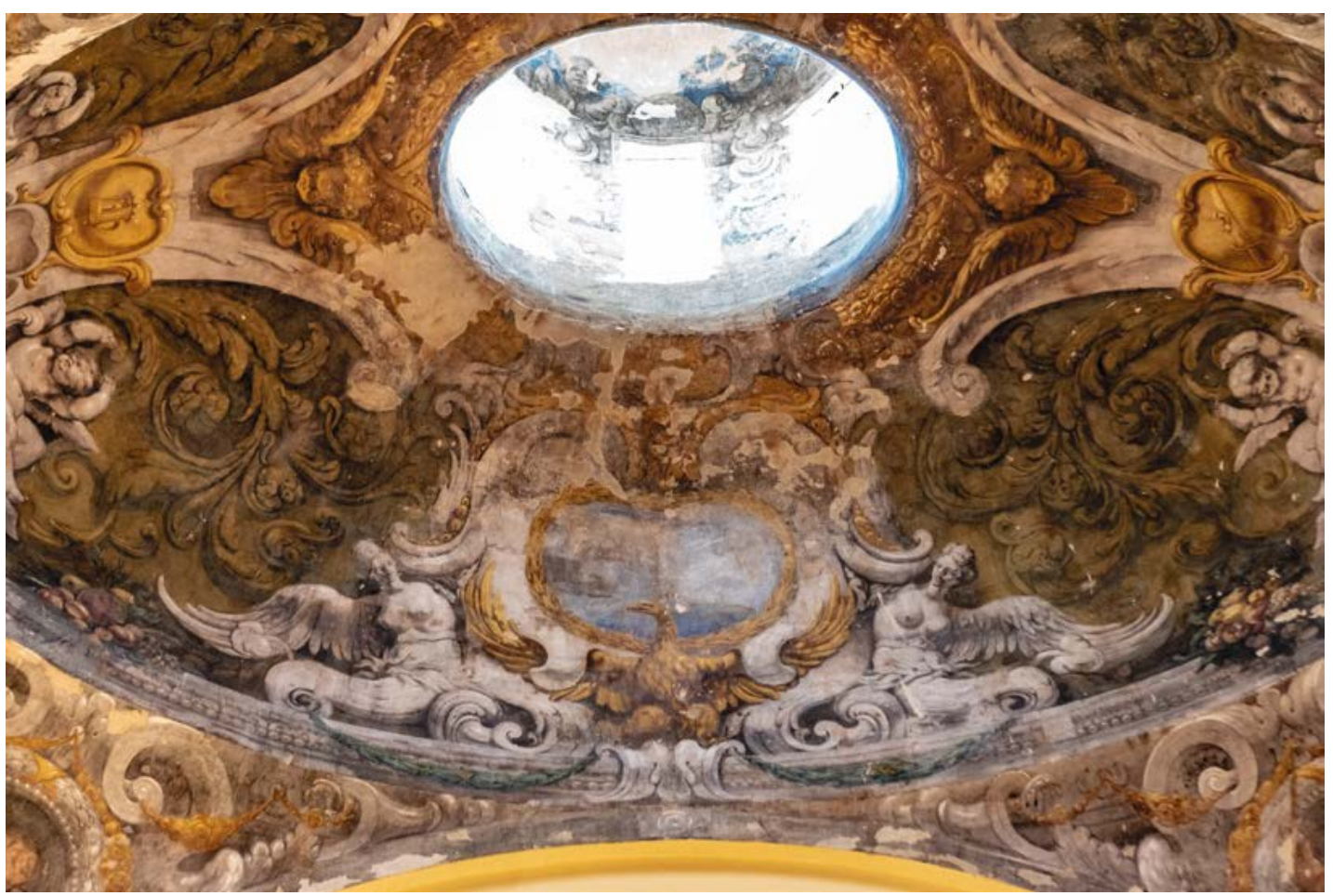

Fig. 7. Vista parcial de la cúpula de la Pasión de La Mantería. Foto cortesía de Javier Domingo.

Fig. 8. Sebastián Muñoz, Proyecto para la decoración de las cúpulas de los brazos del crucero de La Mantería. Biblioteca Nacional de España, Madrid.

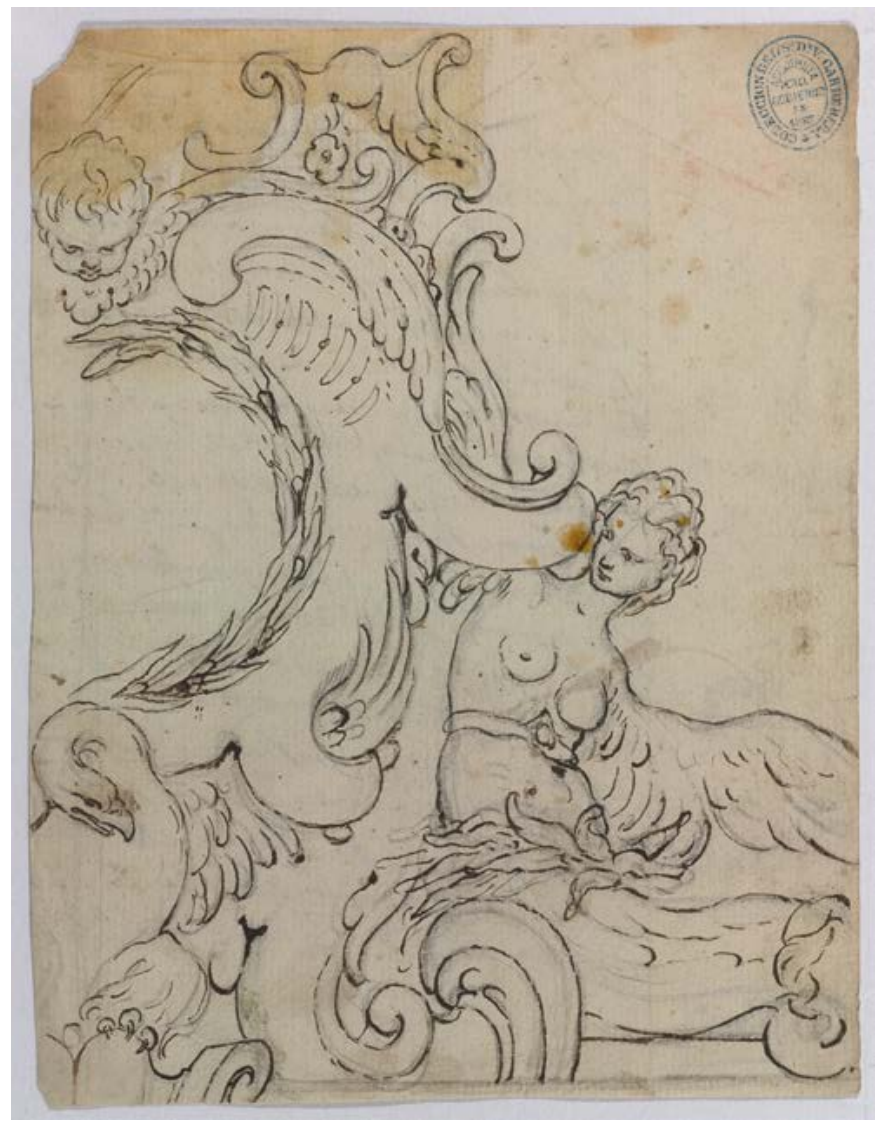

Archivo Español de Arte, vol. XCIII, n. ${ }^{\circ}$ 372, pp. 335-346, octubre-diciembre 2020 ISSN: 0004-0428, eISSN: 1988-8511, https://doi.org/10.3989/aearte.2020.22 


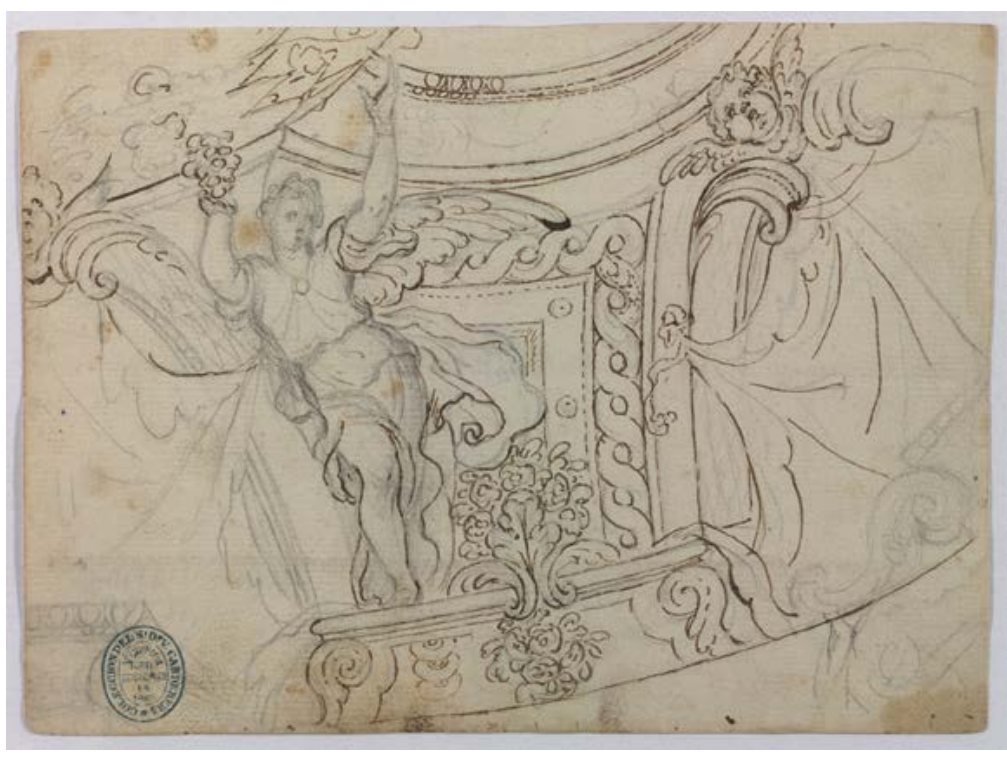

Fig. 9. Sebastián Muñoz, Proyecto para la decoración de la cúpula del presbiterio de La Mantería. Biblioteca Nacional de España, Madrid.

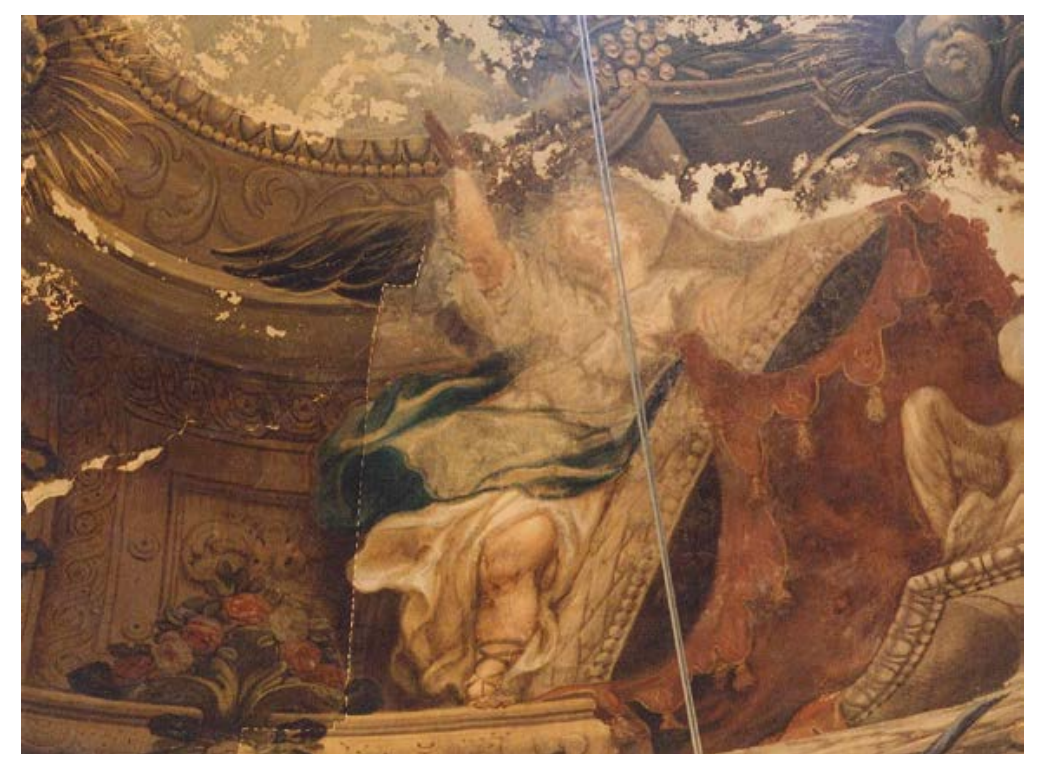

Fig. 10. Detalle de la cúpula del presbiterio de La Mantería. Foto cortesía de María Jesús Boned.

En el reverso, figura escrito un texto en italiano, de difícil lectura, un fragmento de una carta fechada en Zaragoza el 25 de marzo de 1685, dato de gran interés que confirma la presencia de Coello y Muñoz en la ciudad en esa fecha ${ }^{41}$.

El último dibujo, catalogado como anónimo romano del siglo XVII, con el título de Estudio para la decoración de una pechina ${ }^{42}$ [fig. 9], corresponde a una sección de la cúpula del presbiterio, en concreto, a la situada justo encima del altar mayor, como se puede apreciar en la imagen, pese a los desafortunados repintes posteriores [fig. 10].

${ }^{41}$ Según Palomino, concluida la decoración de La Mantería, Muñoz y Coello volvieron juntos a Madrid (Palomino de Castro y Velasco, 1796: 640).

42 VV. AA., 1991: 198, núm. 275. Signatura: DIB/18/1/3909. Lápiz negro y tinta marrón sobre papel verjurado ahuesado. $155 \times 210 \mathrm{~mm}$. 


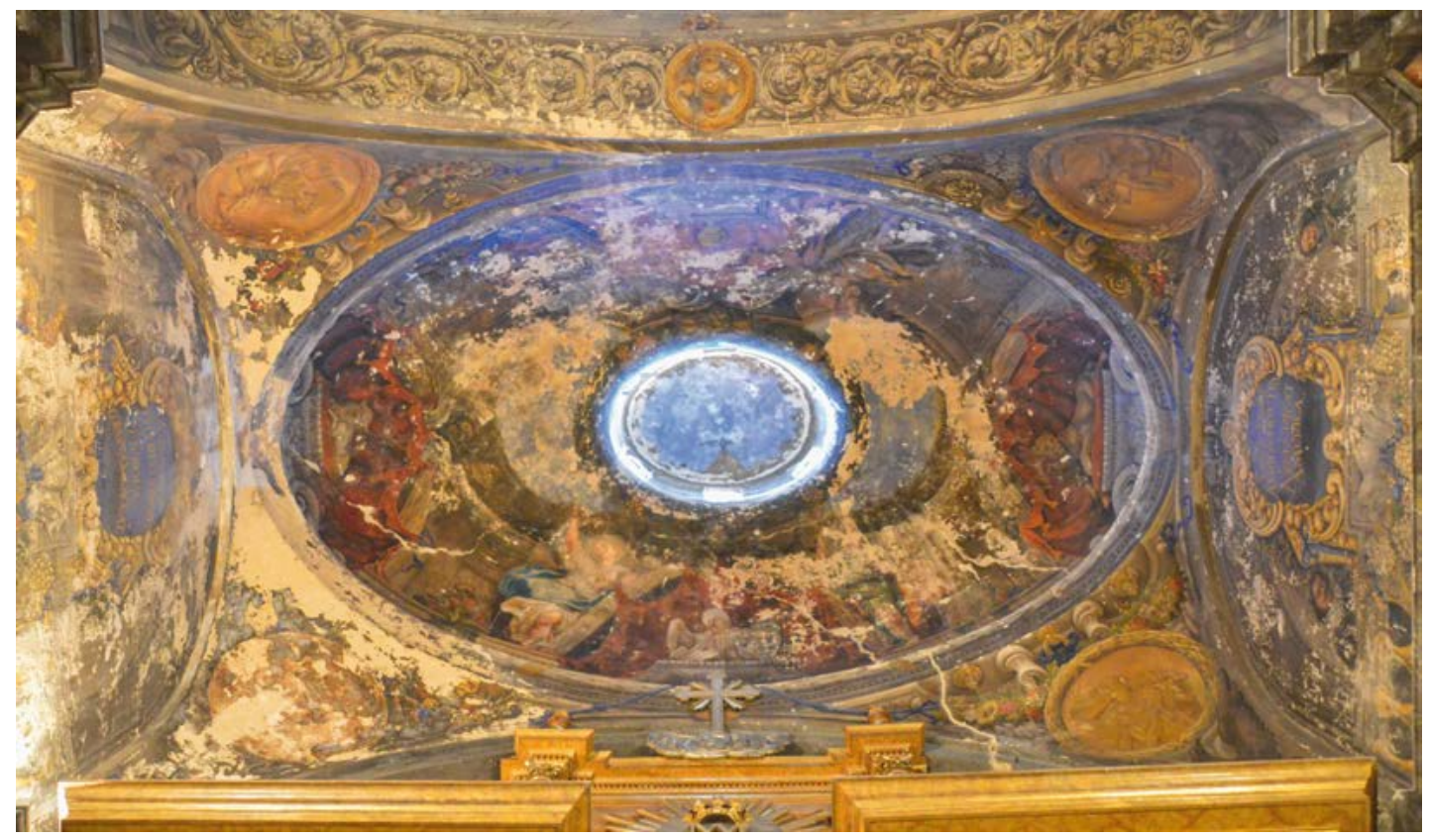

Fig. 11. Vista general de la cúpula del presbiterio de La Mantería. Foto cortesía de Javier Domingo.

Sobre el marco arquitectónico, destaca la figura de un hermoso ángel adolescente que sostiene en alto un racimo de uvas, símbolo del vino consagrado durante la misa, mientras que la cornisa se cubre con cabezas aladas de angelitos entre roleos que, junto con hojas de acanto, ramos de flores, colgaduras..., completan la decoración. En el reverso figura un esbozo para uno de los angelitos sentados sobre roleos que decoran las cúpulas de los brazos del crucero.

Para esta cúpula, Muñoz diseñó unas arquitecturas que dejan ver el cielo. En cada uno de los extremos de los ejes se abre un nicho fingido, cuyo interior aloja un símbolo de Cristo bajo ricas colgaduras. En los extremos del eje menor, cada nicho aparece flanqueado por una pareja de ángeles adolescentes. Las pechinas se decoran con grandes medallones dorados y guirnaldas de flores y frutas, que cuelgan del techo asidas de cintas de color azul [fig. 11].

Su programa iconográfico es una exaltación de la Eucaristía y de la Iglesia Católica. Sobre el altar, el Pelícano, ave capaz de rasgarse el pecho para dar de comer a sus polluelos ${ }^{43}$; en el lado opuesto, la Sagrada Forma. En los extremos del eje mayor, el Agnus Dei o Cordero de Dios y el León de Judá. En las pechinas se representan las alegorías de los cuatro continentes sostenidas por águilas, con las que se significa la universalidad de la Iglesia: en el lado del Evangelio, Asia, con el incensario, y Europa, con cruz y corona, con estas inscripciones en el arco: ASIA DAT THURIS HONORIS. EUROPA CORONAM SACRAT. (Asia ofrece los honores del incienso. Europa consagra la corona.); en el lado de la Epístola, África, acompañada del Sol, y Améri$c a$, con flechas y carcaj, con estas otras inscripciones: SOLE FERT AFRICA FRUCTUS. ARMA DICAT AMERICA. (Âfrica con el Sol produce frutos. América consagra las armas.), símbolos elegidos de la Iconología de Ripa ${ }^{44}$.

Como colofón al magnífico trabajo realizado por Coello y su antiguo discípulo, del que el maestro debió de sentirse satisfecho, ambos se retrataron en el arco de la Epístola, a uno y otro lado de la cartela, de pie, detrás de la barandilla, desde donde parecen contemplar su obra. Coello viste a la española, con traje de paño negro ${ }^{45}$ y golilla, acompañado de su firma escrita sobre un

43 Bernat Vistarini/Cull, 1999: 633.

44 Ripa, 1987, vol. 2: 102-108.

45 Sería negro, pero parece marrón a causa de los repintes. 
tarjetón de papel blanco que pende del barandal: "Claudius Coello fat Pic. Reg. anno 1685". Muñoz pudiera ir vestido de raso con valona, probablemente con traje italiano o a la italiana.

\section{BIBLIOGRAFÍA}

Aterido, Ángel (2002): “Sebastián Muñoz. Dos academias masculinas". En: De la Mano, José Manuel (ed.): Trazos de las Luces. Dibujos españoles del siglo XVIII (cat. exp.). Madrid: José Manuel de la Mano Galería de Arte, pp. 13-17.

Aterido, Ángel (2016): “Sebastián Muñoz”. En: Navarrete Prieto, Benito (dir.): I segni nel tempo. Dibujos españoles de los Uffizi (cat. exp.). Madrid: Fundación Mapfre, pp. 276-280.

Bernat Vistarini, Antonio/Cull, John T. (1999): Enciclopedia de emblemas españoles ilustrados. Madrid: Ediciones Akal. Boubli, Lizzie (2002): Musée du Louvre, Département des Arts graphiques. Inventaire général des dessins. École Espagnole $X V I^{e}-X V I I I^{e}$ siécle. París: Réunion des Musées Nationaux.

Cean Bermúdez, Agustín (1800): Diccionario histórico de los más ilustres profesores de las Bellas Artes en España, tomo tercero. Madrid: Real Academia de San Fernando.

Chamoso Lamas, Manuel (1953): Las pinturas de las bóvedas del convento de la Mantería de Zaragoza, Cuadernos de Arte Aragonés, núm. 4. Zaragoza: Institución "Fernando el Católico" de la Diputación Provincial de Zaragoza.

Claver Ferrer, Antonio (2000): Noticias Historiales del Conbento de Nuestro Padre San Augustín de Çaragoza y de los demás del Reyno de Aragón. Madrid: Editorial Revista Agustiniana.

Guerra Sánchez-Moreno, Esperanza (1931): "La Casa de Panadería”. En: Revista de la Biblioteca, Archivo y Museo, vol. 8, núm. 32, Madrid, pp. 363-391.

Latre González, Gloria M. ${ }^{\text {a }}$ (1984): "Programa iconográfico de la decoración mural de la iglesia de Santo Tomás de Villanueva". En: Artigrama, Revista del Departamento de Historia del Arte de la Universidad de Zaragoza, núm. 1, Zaragoza, pp. 227-252.

López Gómez, José Manuel/Senserrich Espuñes, Rosa (2001): “«La Mantería». Pinturas murales de la Iglesia de Santo Tomás de Villanueva”. En: Restauración \& Rehabilitación, Revista Internacional del Patrimonio Histórico, núm. 49, Madrid, pp. 46-53.

Lorenzo Lizalde, José Ignacio/Soro, Joaquín (2008): “Iglesia de Santo Tomás de Villanueva (La Mantería)”. En: Menor Monasterio, Francisco/Bustos Moreno, Carlos/Conde-Salazar Gómez, José María (eds.): Tres restauraciones en Zaragoza. Basílica del Pilar, Iglesias de Santa María Magdalena y de Santo Tomás (La Mantería). Madrid: Fundación ACS, pp. 175-197.

Martínez Ripoll, Antonio (1985): “Sebastián Muñoz, pintor de María Luisa de Orleáns”. En: Archivo Español de Arte, núm. 232, pp. 332-350.

Martínez Ripoll, Antonio (2008): "Retórica del poder, persuasión de la pintura. La capilla ardiente de María Luisa de Orléans, por Sebastián Muñoz”. En: Navarrete Prieto, Benito (coord.): Fuentes y modelos de la pintura barroca madrileña. Madrid: Editorial Arco/Libros, pp. 205-243.

Monedero Granados, Cristina (1999): "La Iglesia de Santo Tomás de Villanueva”. En: La Mantería, Revista de la Escuela Taller, núm. 1, Zaragoza, pp. 17-21.

Palomino de Castro y Velasco, Antonio (1796): El Parnaso español pintoresco laureado. Madrid.

Paniagua Miguel, Ricardo (2009): "El Colegio Agustino de Sto. Tomás de Villanueva de Zaragoza llamado de La Manteria". En: Revista Agustiniana, vol. 50, núm. 151, Guadarrama (Madrid), pp. 101-137.

Pérez Sánchez, Alfonso Emilio (1986): Historia del dibujo en España. De la Edad Media a Goya. Madrid: Ediciones Cátedra.

Pérez Sánchez, Alfonso Emilio (2003): Catálogo de la colección de dibujos del Instituto Jovellanos de Gijón. Oviedo: Ayuntamiento de Gijón/KRK ediciones.

Réau, Louis (1996-1997): Iconografia del Arte Cristiano, 5 vols. Barcelona: Ediciones del Serbal.

Revenga Domínguez, Paula (2002): Pintura y sociedad en el Toledo barroco. Toledo: Servicio de Publicaciones de la Junta de Comunidades de Castilla-La Mancha.

Ripa, Cesare (1987): Iconología, 2 vols. Madrid: Ediciones Akal.

Rojas Serrano, M. ${ }^{\mathrm{a}}$ Isabel (2000): "La Iglesia y Colegio de Santo Tomás de Villanueva: Apuntes para una historia revisada”. En: La Mantería, Revista de la Escuela Taller, núm. 2, Zaragoza, pp. 43-52.

Roses Lozano, Joaquín (comisario) (2012): Góngora. La estrella inextinguible. Magnitud estética y universo contemporáneo (cat. exp.). Madrid: Sociedad Estatal de Acción Cultural.

Sullivan, Edward J. (1989): Claudio Coello y la pintura barroca madrileña. Madrid: Editorial NEREA.

VV. AA. (1991): Dibujos de arquitectura y ornamentación de la Biblioteca Nacional. Siglos XVI y XVII. Madrid: Ministerio de Cultura-Biblioteca Nacional/Fundación Cultural COAM/Entrecanales y Tavora.

Zapata Fernández de la Hoz, María Teresa (2000): La entrada en la Corte de María Luisa de Orleans. Arte y Fiesta en el Madrid de Carlos II. Madrid: Fundación de Apoyo a la Historia del Arte Hispánico.

Fecha de recepción: 29-III-2020

Fecha de aceptación: 15-VII-2020 